\title{
Diffusion of chemicals into archaeological waterlogged hardwoods obtained from the Thang Long Imperial Citadel site, Vietnam
}

\author{
Nguyen Duc Thanh $^{1} \cdot$ Soichiro Wakiya ${ }^{2} \cdot$ Kazutaka Matsuda $^{2} \cdot$ Bui Duy Ngoc $^{3} \cdot$ Junji Sugiyama $^{1,4} \cdot$ Yohsei Kohdzuma $^{2}$
}

Received: 20 December 2017 / Accepted: 29 July 2018 / Published online: 31 August 2018

(c) The Japan Wood Research Society 2018

\begin{abstract}
This study shows a method to easily develop suitable impregnation procedure of chemicals for preserving the archaeological waterlogged wood (WW) using diffusion constant. The steady-state diffusion coefficients of polyethylene glycol 4000 (PEG4000), trehalose, and keratin through eight archaeological waterlogged wood species were obtained from the total amounts of the chemicals diffused through the wood samples. The diffusion coefficients were strongly affected by the anatomical structures of the wood species and degree of wood deterioration. Within the same species of wood, the highest diffusion rates were measured in the longitudinal direction, followed by those in the radial and tangential directions. The longitudinal diffusion coefficients were 1.5- to 8.1-times higher than the radial diffusion coefficients, which were in turn approximately 1.1- to 5.7-times higher than the tangential diffusion coefficients. The diffusion rates were found to be inversely proportional to the molecular weight of the diffusing chemical. The diffusivity of trehalose through the waterlogged woods was found to be higher than those of keratin and PEG4000. This study provides a potential method to easily estimate chemical diffusion coefficients for dip-diffusion treatments.
\end{abstract}

Keywords Archaeological waterlogged wood $\cdot$ Diffusion rate $\cdot$ Polyethylene glycol $\cdot$ Trehalose $\cdot$ Keratin

\section{Introduction}

Archaeological waterlogged wood (WW) often shows extreme levels of shrinkage and deformation upon drying owing to the high degree of wood-tissue degradation $[1,2]$. Chemical hydrolysis and deterioration by microorganisms in the wet underground environment cause microvoids in the wood cell walls to become larger, increasing the porosity of the wood. However, as long as these voids remain filled with water, WW can retain its shape [3, 4]. Therefore, the water that fills the wood structure must be replaced with an appropriate consolidation agent to protect the wooden

Yohsei Kohdzuma

y-kozuma@nabunken.go.jp

1 Research Institute for Sustainable Humanosphere, Kyoto University, Uji, Kyoto 611-0011, Japan

2 Nara National Research Institute for Cultural Properties, 2-9-1 Niyo-cho, Nara 630-8577, Japan

3 Vietnamese Academy of Forest Science, Duc Thang, Bac Tu Liem, Hanoi, Vietnam

4 College of Materials Science and Engineering, Nanjing Forestry University, Nanjing 210037, China object against shrinkage, collapse, and deformation during drying [5-7]. Water in the lumens of a wood sample can be easily replaced, but it is usually also necessary to replace the water in the cell walls of the wood. Thus, the dimensional stability of a treated sample depends upon the amount of conservation agent in the wood and the ability of the agent to penetrate the cell walls of the sample [8].

The diffusional replacement of water in WW has been investigated with a range of different chemical agents, including sugars (saccharose, lactose, trehalose) [9, 10], polyethylene glycols (PEGs) of different molecular weights (PEG300-PEG6000) [3, 11-15], polymerizable monomers and cross-linkable precondensates (e.g., melamine and phenolic resins) [16], and keratin [17]. Furthermore, the conservation of WW has been performed using several types of diffusion technologies, including multi-spraying, long-term immersion, bandaging, panel impregnation, and pressurediffusion techniques [8].

The diffusion of a conservation agent into WW sample depends upon several factors, including the temperature of the treatment $[18,19]$. It is well known that an increase in temperature increases solute diffusion coefficients considerably [20,21]. On the other hand, the rate of solute diffusion 
through a wood sample decreases with growing solute molecular weight $[11,12,18,22]$. The diffusion of chemical depends on the species of wood (e.g., Scots pine, spruce, oak, or birch $[12,18,19,23])$, the direction of diffusion through the wood [18, 19, 23-25], and moisture content of the wood [19]. Furthermore, in some species (e.g., Pinus radiata), differences in diffusion rates between the sapwood and heartwood can occur owing to heartwood formations, tylosis, and/or the deposition of calcareous materials that reduce the diffusion of solutes through the wood [26, 27].

An important consideration in the treatment of archaeological wood is the period of time taken to impregnate the artifact with the consolidating solution [6,7]. The processes involved in the diffusion of such solutions through fresh timber have been investigated in previous studies $[22,25$, 28]. However, the area of archaeological WW conservation has received little research attention owing to practical and experimental difficulties and the wide variation in the characteristic properties of archaeological wood samples [6, 29-31].

It will only be possible to confidently predict the durations required for WW treatments when the diffusion rates of consolidating agents into different types of WW are quantitatively established. Consequently, this study was aimed to identify effective chemicals and to predict the period of time required for the impregnation, and the purpose of the present research was to clarify the influence of wood species and deterioration on the steady-state diffusion coefficients of chemicals through WWs. Identifying effective consolidation agents for WW conservation will allow the preservation of historic resources for future generations.

\section{Materials and methods}

\section{Samples preparation}

Eight archaeological WW samples were collected from the Thang Long Imperial Citadel site in Hanoi, Vietnam, which is a member of the UNESCO World Heritage list. The decayed outer layers of the original blocks of WWs were removed to give a relatively uniform inner core with minimum defects. The inner core from each block was divided into four adjacent parts. For anatomical characterization, small specimens, approximately $5 \times 5 \times 5 \mathrm{~mm}$ (tangential $\times$ radial $\times$ longitudinal dimensions), were prepared by manual cutting of the core part with razor blades. For chemical analysis, the inner core part was air-dried and powdered in a coffee grinder, and the measurement was carried out on sieved material (in the range 60-100 mesh, corresponding to $0.15-0.25 \mathrm{~mm}$ ). In examination of physical properties, the core part was cut into $20 \times 20 \times 10 \mathrm{~mm}$ (tangential $\times$ radial $\times$ longitudinal dimensions). Finally, the inner core part was cut into $40 \times 40 \times 5 \mathrm{~mm}$ specimens for diffusion experiments, and diffusion along the 5-mm dimension was measured.

PEG1500 (Mw: 1,450) were purchased from Wako Pure Chemical Industries, Japan. PEG4000 (Mw: 3,350) were purchased from Sanyo Chemical Industries, Japan. Trehalose (TREHA ${ }^{\circledR}$, Mw: 342 ) was obtained from Hayashibara, Japan, and feather keratin powder (KERATIDE ${ }^{\circledR}$, TK-B, Mw: approximately 750) was purchased from the Toyo Feathers Company, Japan. All chemicals were used without further purification. Silicone rubber (KE 12) was obtained from Shin-Etsu Chemical Co., Ltd., Japan.

\section{Anatomical characterization}

Small specimens were embedded in a series of increasing concentration of PEG1500 bath at $60{ }^{\circ} \mathrm{C}$ to fix the wood cell walls. In the final stage fixation, the specimen was immersed in 100\% PEG1500 and then air-dried. 20-30 $\mu \mathrm{m}$ radial, tangential, and longitudinal sections were cut from each sample using a microtome (TU-213, Yamato Scientific Co., Ltd., Japan). The sections were immersed in water at $60{ }^{\circ} \mathrm{C}$ for $6 \mathrm{~h}$ to remove the PEG1500. The sections were then stained in $1 \%$ safranin for $2 \mathrm{~h}$ and then dehydrated using ethanol solutions of increasing concentration. After dehydration, the sections were mounted on glass slides and observed using an optical microscope (BX51; Olympus, Tokyo, Japan) under $5 \times, 10 \times$, and $20 \times$ magnifications. Identification was performed with the help of the literature and reference databases from Xylarium, Research Institute for Sustainable Humanosphere, Kyoto University, and the Vietnamese Academy of Forest Sciences.

\section{Physicochemical properties}

The physical parameter such as moisture content and basic density can be measured to evaluate the state of degradation of WWs [31]. The saturated moisture contents $\left(U_{\max }\right)$ were determined by weighing the wood samples before and after oven drying at $105{ }^{\circ} \mathrm{C}$. The basic wood density was calculated based on the oven-dried weight of wood sample and its saturated moisture volume.

In the next stage of the experiment, chemical analysis was carried out on sieved material. The percentage content of main wood components (extractives, lignin, holocellulose and cellulose) was determined were determined in triplicate by chemical analysis. Solvent extractive components were measured according to TAPPI standards [32, 33]. Lignin content was measured according to the TAPPI standard [34]. Holocellulose content was determined according to the procedure described [35] using an acid solution of sodium chlorite. Cellulose was calculated according to the TAPPI standard using sodium hydroxide solution [36]. The 
acid soluble lignin (ASL) is measured by conventional UV spectrophotometric method using the absorption at $205 \mathrm{~nm}$ (UV-1800, Shimadzu, Japan).

\section{Experimental procedures}

Diffusion of the chemicals through the WWs was measured using a diffusion cell based on a design used in previous studies [18, 37]. A wood specimen was held between the two cups of the diffusion cell (Fig. 1). To eliminate the effect of pressure on transfer, constant head devices (Mariotte's bottle) were connected to each side of the cups. Each side of the cup contained $1000 \mathrm{ml}$ of liquid. The specimen was saturated in distilled water at a low pressure of $0.1 \mathrm{MPa}$ for $1 \mathrm{~h}$. Then, the sample was fixed in the diffusion cell using silicone rubber to allow diffusion to occur along the required direction. It was manufactured to have an inside cross-sectional $(A)$ of $30 \times 30 \mathrm{~mm}^{2}$. Once the diffusion cell was set up, one side of the cell was filled with distilled water (cell $\mathrm{C}_{2}$ ) and the other side with a $10 \%(\mathrm{w} / \mathrm{w})$ PEG, trehalose, or keratin aqueous solution (cell $\mathrm{C}_{1}$ ).

The apparatus was maintained at a temperature of $28^{\circ} \mathrm{C}$. The chemical agent was allowed to diffuse through the wood sample along the concentration gradient, and the liquid in both side of diffusion cell was sampled at regular intervals for analysis. $2 \mathrm{ml}$ of the liquid sample on each cup was taken until a steady-state flow was achieved. The solute was determined using an oven-dryer (EYALA NDS-450D, Tokyo Rikakikai Co. Ltd., Japan). The liquid samples were dried at $80^{\circ} \mathrm{C}$ for $6 \mathrm{~h}$ then at $105^{\circ} \mathrm{C}$ until a constant weight was achieved. The concentration of solution in both side of diffusion cell, namely $c_{1}$ and $c_{2}$, was used in estimation of diffusion coefficient using Eq. 4.

\section{Calculation of diffusion coefficient}

In steady-state diffusion along a direction, the diffusion is described by Fick's first law in one spatial dimension using steady-state coefficient $D$ :

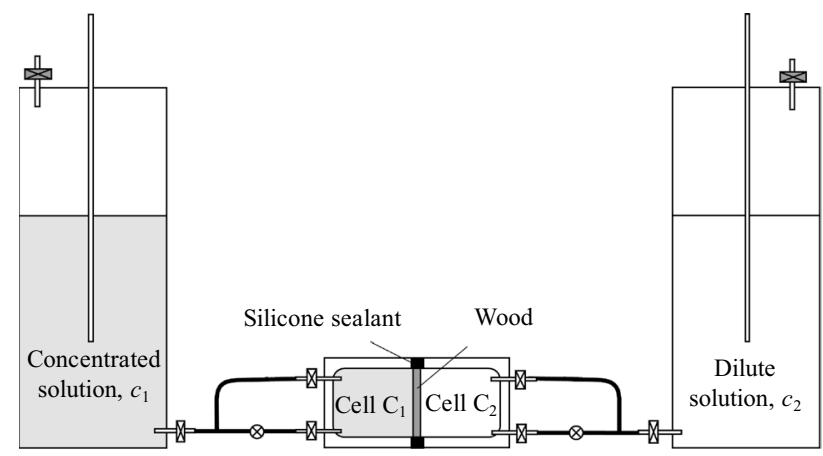

Fig. 1 Diffusion apparatus
$J=-D \frac{d_{c}}{d_{x}}$,

where $x$ represents a position (m) along the direction of diffusion, and $c$ and $J$ represent the concentration $\left(\mathrm{kg} / \mathrm{m}^{3}\right)$ and the flux $\left(\mathrm{kg} /\left(\mathrm{m}^{2} \times \mathrm{s}\right)\right)$ of solute at a position, respectively.

In this study, the quantity of solute diffusing across a cross-sectional area with $A\left(\mathrm{~m}^{2}\right)$ per unit of time is defined as $Q_{\mathrm{t}}(\mathrm{kg} / \mathrm{s})$, which can be related to the flux as the following equation:

$Q_{\mathrm{t}}=J A$.

The $Q_{\mathrm{t}}$ was determined by calculating the concentrations of solute in the dilute solutions $\left(c_{2}\right)$ at regular intervals $(t)$ until a steady-state flow was reached.

$Q_{\mathrm{t}}=\frac{c_{2}}{100 t}$.

The following equation is deduced from Eqs. (1) and (2):

$\frac{d_{c}}{d_{x}}=-\frac{Q_{\mathrm{t}}}{D A}$,

The steady-state diffusion coefficient is obtained by the integration of $c$ with respect to $x$ as follows:

$D=\frac{Q_{\mathrm{t}} l}{A\left(c_{1}-c_{2}\right)}$.

where $l$ is the diffusion length (m), $c_{1}$ and $c_{2}$ are the concentrations of solute in the concentrated and dilute solutions at positions of $x=0$ and $x=1$, respectively.

\section{Results and discussion}

\section{Anatomical characterization}

Based on their diagnostic anatomical features, a total of eight different taxa were identified (Table 1). Generally, the identification reached the genus level. However, one of the timber samples could be identified to the species level owing to its historical and traditional relevance, i.e., Erythrophleum fordii Oliv. Because of the high-quality wood of $E$. fordii, it has been used as traditional timber in many historical buildings in Vietnam.

\section{Evaluation of wood deterioration}

Figure 2 shows the physical properties of all evaluated WWs. A higher moisture content is associated with the lower basic density of WW. The high $U_{\max }$ values, i.e., from 315 to $621 \%$, while the basic density of wood was between 0.14 and $0.25 \mathrm{~g} / \mathrm{cm}^{3}$, are typical of medium-to-heavily-degraded 


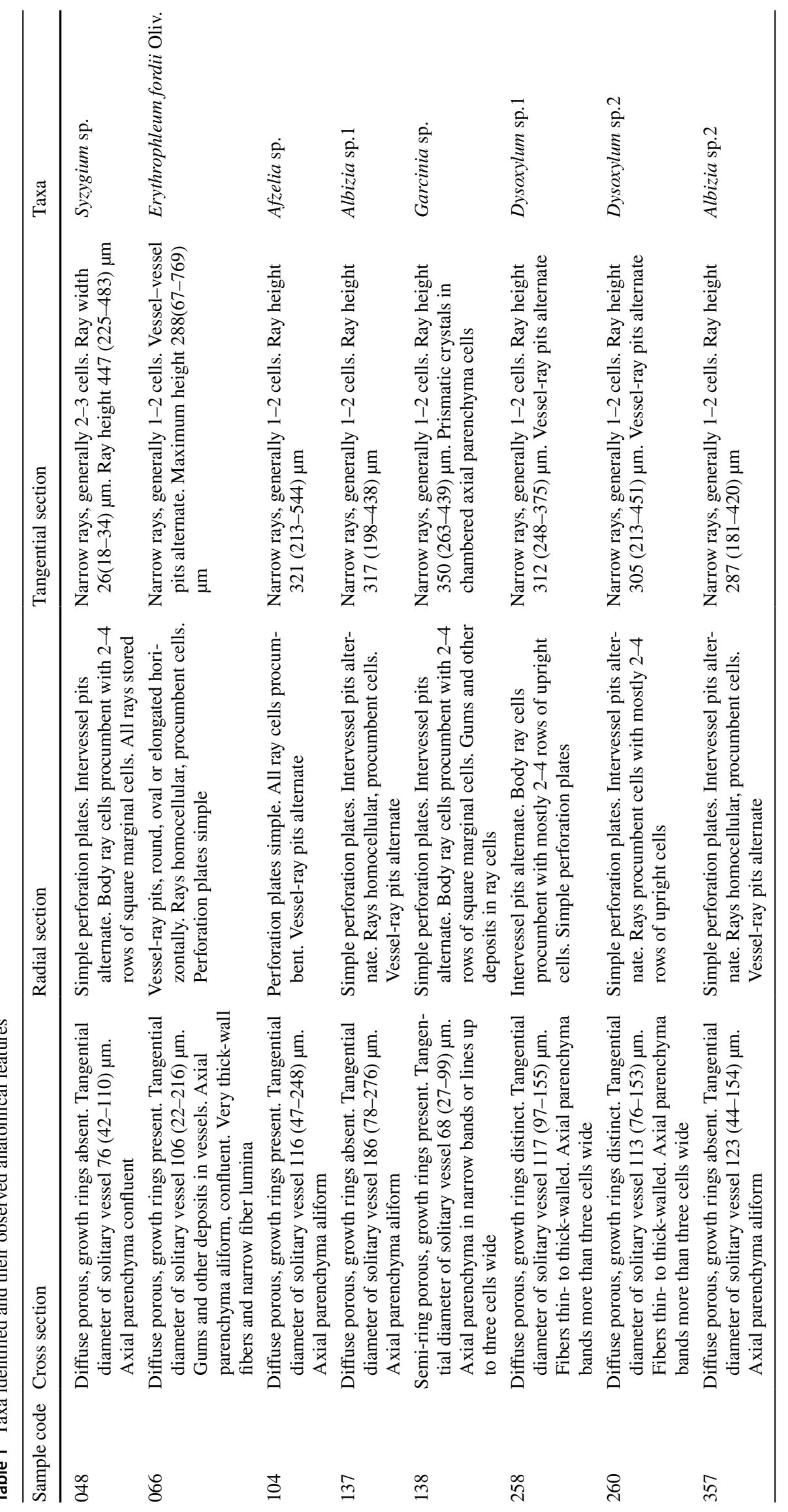


Fig. 2 Relationship between basic density and the saturated moisture content. The bars represent the standard deviations

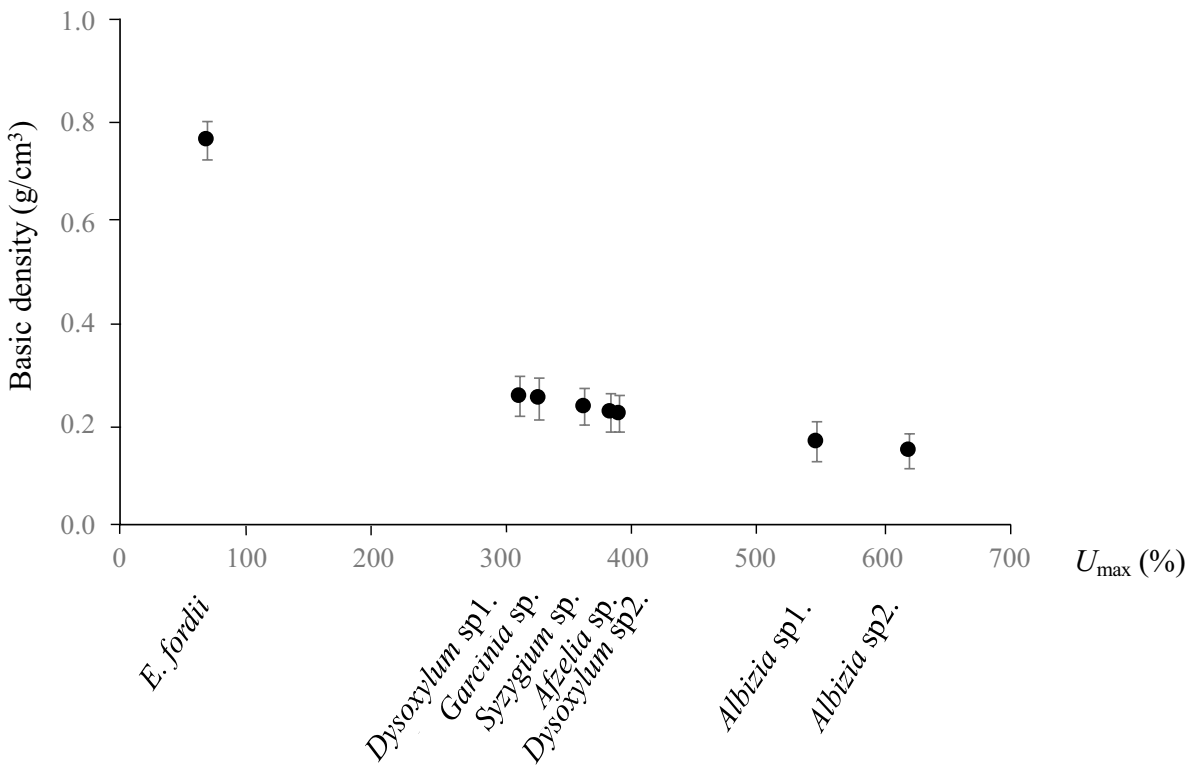

wood [6]. On the other hand, the $U_{\max }$ for $E$. fordii wood was only $68 \%$ and basic density was $0.76 \mathrm{~g} / \mathrm{cm}^{3}$, indicating that this species was still in good condition. An increase in $U_{\max }$, as well as a decrease in basic density, indicates an increase in the degree of wood degradation $[5,6]$.

Furthermore, an evaluation of chemical composition is valuable to assess the wood degradation (Fig. 3). The holocellulose content of WWs ( $U_{\max }$ more than $300 \%$ ) was considerably reduced to between 25 and $35 \%$, while the lignin content raised to merely $75 \%$. According to previous studies, the degradation of WW mainly involves the deterioration of hemicellulose and cellulose, while lignin is the most resistant [6]. Therefore, the low content of holocellulose suggests that cellulose and hemicellulose underwent severe degradation [6, 7]. The cellulose content of these WWs was considerably reduced to between 10 and $14 \%$, while $40 \%$ cellulose has been found in the non-degraded wood [38]. These results indicate the extensive decay of WWs
Fig. 3 Chemical composition of WWs

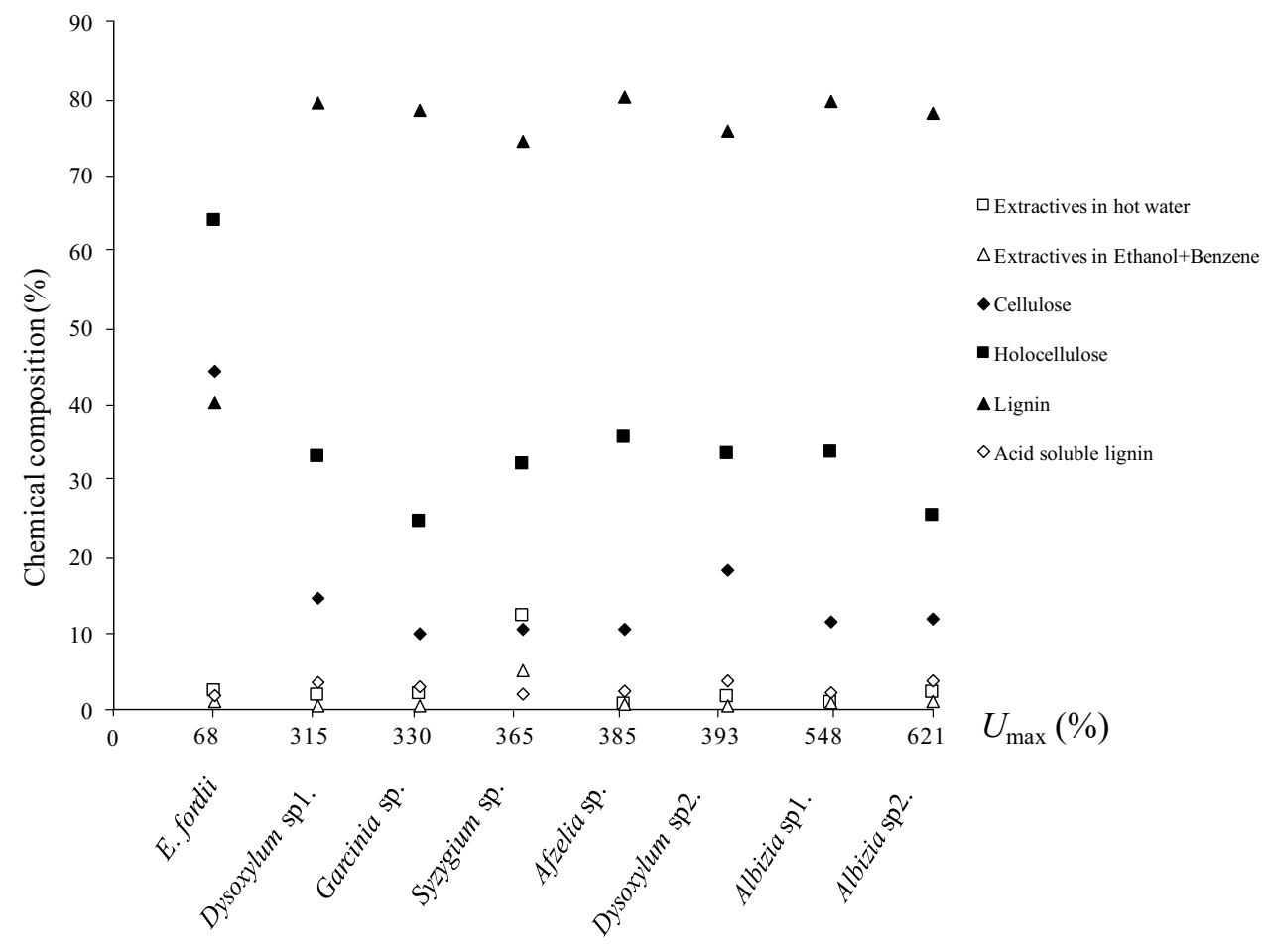


evaluated. Interestingly, holocellulose and lignin content in E. fordii wood were about 65 and $40 \%$, respectively. The results indicate that $E$. fordii was less degraded and its characteristics were quite similar to sound wood.

\section{Extractives}

Total extractives content in WWs ranged from 2 to $3 \%$. However, this value of Syzygium sp. was about 17\%. The extractive content in wood has various effects on wood physical properties, e.g., permeability, as previously reported [39].

\section{Steady-state diffusion coefficients}

Table 2 shows the steady-state diffusion coefficients for the chemicals through the WWs. The values for each species are plotted in Figs. 4, 5, and 6. The variation in the diffusion coefficients is remarkably significant owing to the different wood structures. Within the same timber samples, the diffusion coefficients measured in the longitudinal direction are larger than those in the transverse directions. The diffusivity of a chemical depends on its molecular weight. It is clear that the diffusion coefficient of trehalose through WW samples is extremely high. Subsequently, the diffusion of keratin is relatively smaller than that of trehalose, while the lowest ratio is observed for PEG4000.

The longitudinal diffusion coefficients are shown in Fig. 4. Within the same species, the diffusion of trehalose is faster than that of keratin and PEG4000. The diffusivities of keratin are only slightly higher than those of PEG4000, even though they have very different molecular weights. Figure 4 reveals that there is little correlation between longitudinal diffusivity and saturated moisture content in the wood samples. The highest rates of longitudinal diffusion are observed for Afzelia sp. $\left(U_{\max }=385 \%\right)$, ranging from $8.96 \times 10^{-9}$ to $12.7 \times 10^{-9} \mathrm{~m}^{2} \mathrm{~s}^{-1}$. Similar diffusion rates are observed for Garcinia sp. $\left(U_{\max }=330 \%\right)$ and Albizia sp. $\left(U_{\max }=548\right.$ and $621 \%)$. This may depend on the circumstance that the

Table 2 Steady-state diffusion coefficients for trehalose, keratin, and PEG4000. Unit: $\times 10^{-9} \mathrm{~m}^{2} \mathrm{~s}^{-1}$

\begin{tabular}{|c|c|c|c|c|c|c|c|c|c|c|c|}
\hline \multirow[t]{2}{*}{ No. } & \multirow[t]{2}{*}{ Species } & \multirow[t]{2}{*}{$U_{\max }(\%)$} & \multicolumn{3}{|l|}{ Trehalose } & \multicolumn{3}{|l|}{ Keratin } & \multicolumn{3}{|l|}{ PEG4000 } \\
\hline & & & Longitudinal & Radial & Tangential & Longitudinal & Radial & Tangential & Longitudinal & Radial & Tangential \\
\hline 1 & E. fordii & 68 & 0.62 & 0.39 & 0.36 & 0.50 & 0.24 & 0.23 & 0.24 & 0.15 & 0.09 \\
\hline 2 & Dysoxylum sp.1 & 315 & 6.29 & 2.25 & 1.20 & 2.70 & 1.63 & 1.17 & 2.27 & 1.50 & 1.02 \\
\hline 3 & Garcinia sp. & 330 & 8.93 & 2.34 & 1.72 & 6.66 & 1.80 & 1.55 & 6.07 & 1.70 & 1.19 \\
\hline 4 & Syzygium sp. & 365 & 5.72 & 2.45 & 0.92 & 3.07 & 0.86 & 0.26 & 1.22 & 0.68 & 0.12 \\
\hline 5 & Afzelia sp. & 385 & 12.70 & 2.83 & 1.90 & 10.80 & 2.52 & 1.77 & 8.96 & 2.35 & 1.52 \\
\hline 6 & Dysoxylum sp.2 & 393 & 3.19 & 1.59 & 0.72 & 3.00 & 1.29 & 0.25 & 2.53 & 0.61 & 0.24 \\
\hline 7 & Albizia sp.1 & 548 & 8.12 & 3.59 & 2.95 & 6.79 & 3.29 & 2.13 & 5.78 & 3.08 & 2.00 \\
\hline 8 & Albizia sp.2 & 621 & 6.40 & 1.75 & 1.68 & 5.61 & 1.57 & 1.27 & 5.02 & 0.86 & 0.83 \\
\hline
\end{tabular}

Fig. 4 Steady-state diffusion coefficients for the chemicals in the longitudinal direction

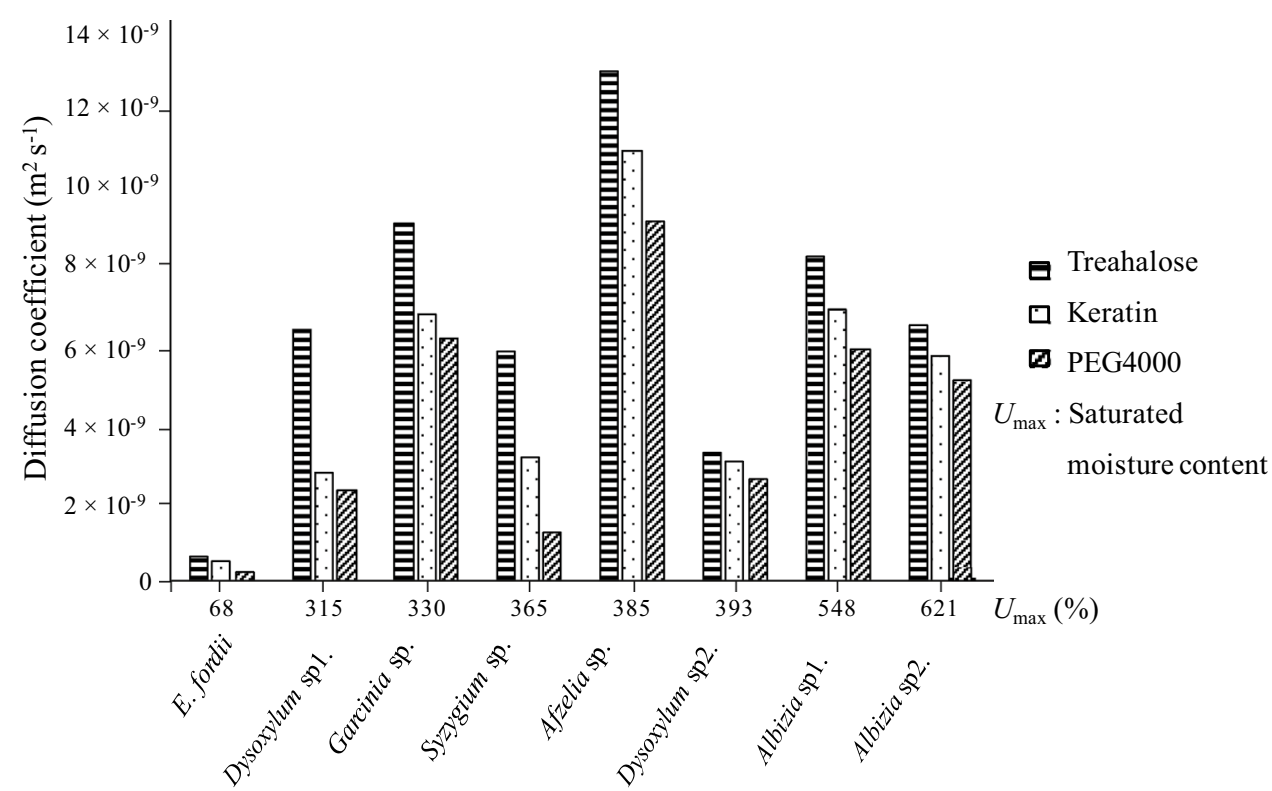


Fig. 5 Steady-state diffusion coefficients for the chemicals in the radial direction

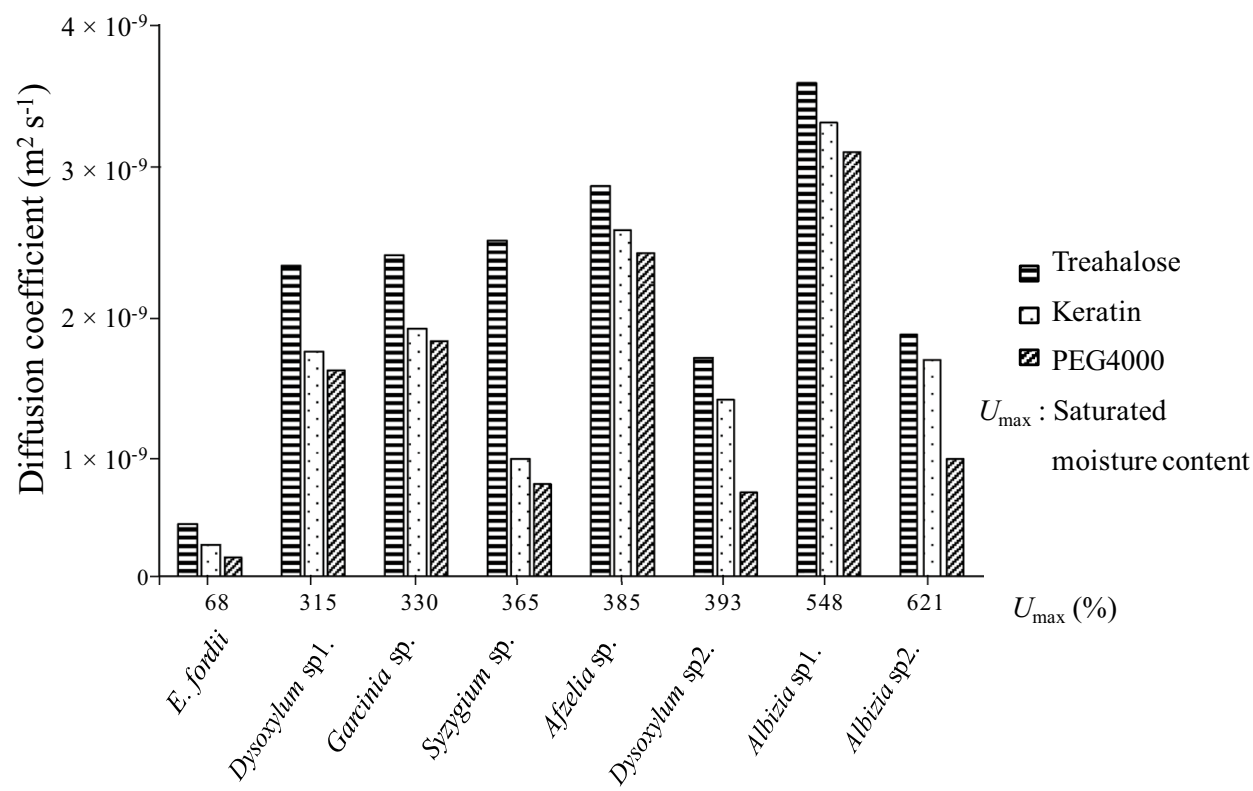

Fig. 6 Diffusion coefficients for the chemicals in the tangential direction

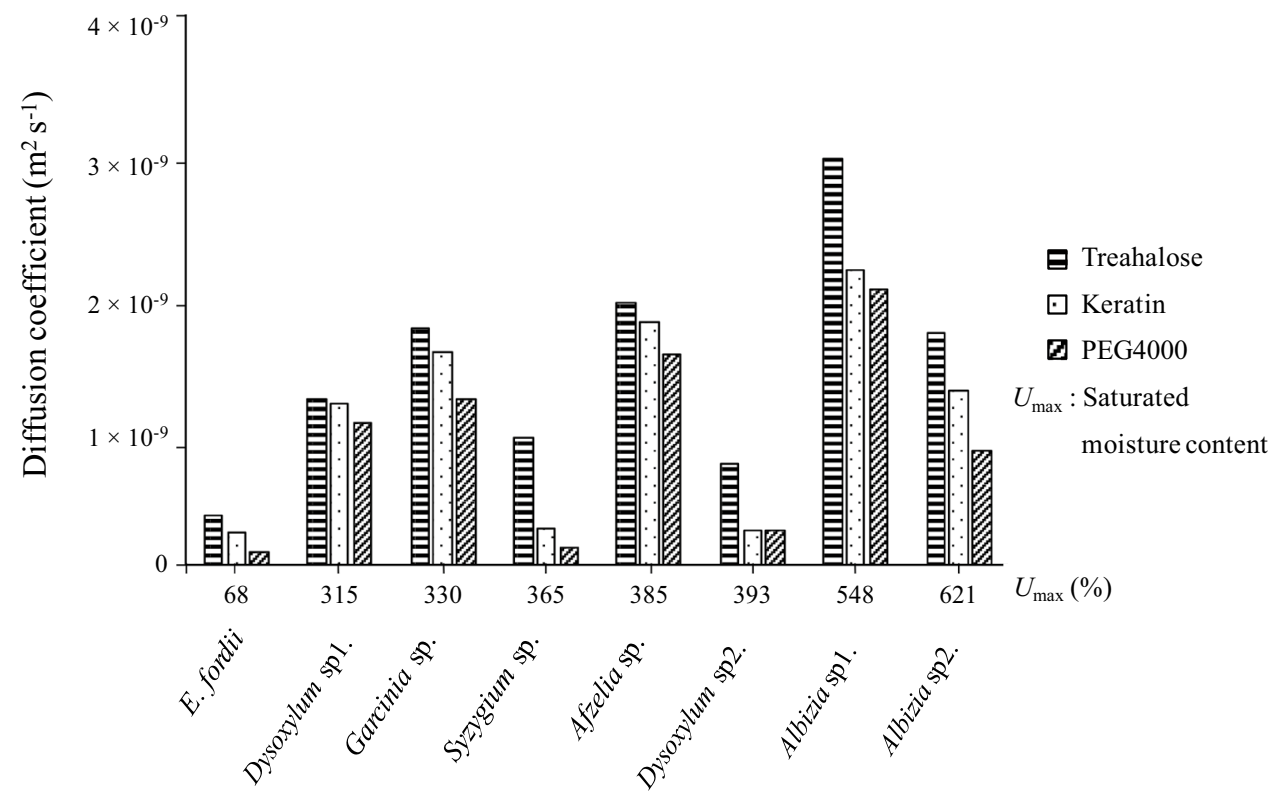

higher $U_{\max }$ in the Afzelia sp. wood might have favored the diffusion of chemical molecules, or that any hindrance to diffusion was present in the Albizia sp. wood (higher $U_{\max }$ values), depending on the difference in the anatomical structures of the hardwood species [12]. Because of their similar structures, the diffusion rates of keratin and PEG4000 in Dysoxylum spp. are quite similar. These values are between $2.27 \times 10^{-9}$ and $3.00 \times 10^{-9} \mathrm{~m}^{2} \mathrm{~s}^{-1}$. The diffusivities of the chemicals are limited in $E$. fordii wood, ranging from $0.24 \times 10^{-9}$ to $0.62 \times 10^{-9} \mathrm{~m}^{2} \mathrm{~s}^{-1}$.

Conversely, the diffusion coefficients along the radial direction had little correlation with $U_{\max }$ (Fig. 5). This is probably due to the anisotropic structure of wood and the presence of deposits that limit diffusion in the ray cells of those species. The diffusion rate for trehalose is higher than that of the other chemicals. Within the same species except for Garcinia sp. ( $\left.U_{\max }=330 \%\right)$, the diffusivity of keratin is higher than that of PEG4000. This may be due to the heterogeneously microporous structures of the specimens.

Similarly, solute diffusivity along the tangential direction was different among the WWs evaluated (Fig. 6). The difference in the structure of WWs can strongly affect diffusivity. The highest rates of diffusion are observed in Albizia sp. $\left(U_{\max }=548 \%\right)$, ranging from $2.00 \times 10^{-9}$ to $2.95 \times 10^{-9} \mathrm{~m}^{2}$ $\mathrm{s}^{-1}$. The diffusivities of the chemicals in E. fordii wood are 
significantly low, varying from $0.10 \times 10^{-9}$ to $0.36 \times 10^{-9}$ $\mathrm{m}^{2} \mathrm{~s}^{-1}$.

Of all the species evaluated, E. fordii presents the lowest rates of diffusion in all directions owing to its low water content and unique structure. The E. fordii wood consists of thick-walled fibers with the lumina almost completely closed. Furthermore, the presence of deposits in some vessels is also likely to be responsible for the low permeability values [40]. The small values of diffusion coefficient were also observed in Syzygium sp. This may be due to very high extractives content that forms an inhibition for diffusion [39]. The diffusion of chemicals in Dysoxylum spp. decreases with increasing $U_{\max }$ although they have similar anatomical features and extractive content (about 2\%). This phenomenon may be interpreted by considering the variation of decay in the wood matrix which produced different amount of water available for transfer of solute, as reported [41]. Similarly, the diffusion of heavily degraded Albizia sp. $\left(U_{\max }=621 \%\right)$ was lower than that with lower degradation $\left(U_{\max }=548 \%\right)$. This situation is probably due to the difference in hemicellulose content between more heavy degradation and milder degradation. Since the hemicellulose is known to absorb the water, the cell walls with the higher hemicellulose content adsorb more water that affected to the value of $D$.

To summary, the variation of diffusion coefficients in this study is probably owing to two fundamental factors. First, the anisotropic structure wood causes the different liquid's flow rate in three-grain directions. The wood consists of cells arranged longitudinally except for the ray cells [42]. Therefore, longitudinal penetration, aided by some liquid flow, is often many times greater than transverse penetration [21]. On the other hand, the wood cells are connected to neighboring cells through numerous intervascular pits $[42,43]$. The pits tend to be oriented tangentially to the center of the tree [7]. Moreover, the presence of wood rays, the abundance of pits on the radial walls, and thicker tangential walls result in the anisotropic structure of wood. This indicates that the liquid's flow rate in the radial direction is often larger than that of tangential direction. Second, the permeability characteristics of WW were extensively modified by the degradation processes. The result of the biological attack in the deposition environment is the gradual weakening of the wood structure through the loss of structurally important material, i.e., cellulose and hemicellulose [6, 7]. Consequently, as the structural material was removed, the porous network became more open, and the amount of water it contains increases, affecting diffusion processes. The broader channels caused by the loss of cell wall material provide enhanced pathways for the transport of preservation agents [44]. In contrast to modern wood, in which the diffusion of chemicals occurs mainly along the cell lumina, the flow paths for diffusing solutes in WW are through the solvent-filled voids, such as the lumen of cell, cell wall voids, and transient capillaries
[19]. However, not all the water in the pores is available for the diffusion of chemicals [44]. Furthermore, tyloses and the deposition of calcareous material may block these routes for diffusion in an archaeological timber [6]. Therefore, the different state of wood deterioration was also affected to diffusion and permeability processes.

\section{Conclusions}

In all WW species evaluated, higher rates of diffusion were observed in the longitudinal direction, followed by those in the radial and tangential directions. The variation of the diffusion coefficient is related to the typical wood structure and deterioration of archaeological wood. Since the degree of deterioration varies widely even though wood samples are cut from the same beams, future study is required to determine additional coefficients for different WW species and samples with different degrees of wood degradation. Equally important, future research on the diffusivity of chemical with different molecular weight, temperature and density is also needed. Although several further experiments are under development for this research, the diffusion coefficients calculated in this study along with the measured dimensions of WW samples from the same species can be used to estimate treatment time. Thus, through our research, it will be possible to safely shorten the period of preservation processing, which is currently decided mainly based on intuition and personal experience, by obtaining diffusion coefficients more accurately.

Acknowledgements The study was partly supported by Grants-in-Aid for Scientific Research (A) No. 25252033, Japan Society for the Promotion of Science, RISH Cooperative Research (database) and RISH Mission Research V, Kyoto University. The authors acknowledge the Thang Long-Hanoi Heritage Conservation Center, Hanoi, and the Institute of Archaeology, Vietnam Academy of Science and Technology for providing the archaeological wood materials.

\section{References}

1. Bugani S, Modugno F, Łucejko JJ, Giachi G, Cagno S, Cloetens P, Janssens K, Morselli L (2009) Study on the impregnation of archaeological waterlogged wood with consolidation treatments using synchrotron radiation microtomography. Anal Bioanal Chem 395:1977-1985

2. Christensen M, Kutzke H, Hansen FK (2012) New materials used for the consolidation of archaeological wood-past attempts, present struggles, and future requirements. J Cult Herit 13S:S183-S190

3. Jiachang C, Donglang C, Jingen Z, Xia H, Shenglong C (2009) Shape recovery of collapsed archaeological wood ware with active alkali-urea treatment. J Archaeol Sci 36:434-440

4. Uzielli L (2009) Wood science for conservation of cultural heritage. In: Proc Int Conf held by COST Action IE0601 Florence. Firenze University Press, Italy 
5. Broda M, Mazela B (2017) Application of methyltrimethoxysilane to increase dimensional stability of waterlogged wood. J Cult Herit 25:149-156

6. Rowell RM, Barbour RJ (1990) Archaeological wood: Properties, chemistry and preservation. Am Chem Soc, Washington DC

7. Pearson C (1987) Conservation of marine archaeological objects. Butterworth Co. Ltd., London

8. Reinprecht L (2016) Wood deterioration, protection and maintenance. Wiley Blackwell, London

9. Babiński L (2015) Dimensional changes of waterlogged archaeological hardwoods pre-treated with aqueous mixtures of lactitol/ trehalose and mannitol/trehalose before freeze-drying. J Cult Herit 16:876-882

10. Morgós A, Imazu S, Ito K (2015) Sugar conservation of waterlogged wood archaeological finds in the last 30 years. In: Proc Conserv Digit National Maritime Museum in Gdańsk, Poland, pp 15-20

11. Tarkow H, Feist WC, Southerland CF (1966) Interaction of wood with polymeric materials penetration versus molecular size. Forest Prod J 16(10):61-65

12. Håfors B (2010) Conservation of the wood of the Swedish warship Vasa of A.D. 1628. Evaluation of polyethylene glycol conservation programmes. PhD thesis, University of Gothenburg, Sweden

13. Olek W, Majka J, Stempin A, Sikora M, Zborowska M (2016) Hygroscopic properties of PEG treated archaeological wood from the rampart of the 10th century stronghold as exposed in the Archaeological Reserve Genius loci in Poznań (Poland). J Cult Herit 18:299-305

14. Giachi G, Capretti C, Donato ID, Macchioni N, Pizzo B (2011) New trials in the consolidation of waterlogged archaeological wood with different acetone-carried products. J Archaeol Sci 38:2957-2967

15. Hocker E, Almkvist G, Sahlstedt M (2012) The Vasa experience with polyethylene glycol: a conservator's perspective. J Cult Herit $13: 175-182$

16. Horie V (2010) Materials for conservation: organic consolidants, adhesives and coatings, 2nd edition. Butterworth-Heinemann, USA

17. Endo R, Sugiyama J (2013) Evaluation of cell wall reinforcement in feather keratin-treated waterlogged wood as imaged by synchrotron X-ray microtomography ( $\mu$ XRT) and TEM. Holzforschung 67:795-803

18. Vinden P (1983) Preservation treatment of wood by diffusion processes. PhD Thesis, University of London, England

19. Dean LR (1993) The conservation and stabilization of ancient waterlogged woods and the diffusion of water-borne polymers through wood. PhD Thesis. University of Portsmouth, England

20. Christensen GN (1951) Diffusion in wood. II. The temperature coefficient of diffusion through wood. Aust J Appl Sci 2(4):430-439

21. Tamblyn NE (1985) Treatment of wood by diffusion. In: Findlay WPK (ed) Preservation of timber in the tropics. Forestry Sci, vol 17. Springer, Dordrecht

22. Fukuyama M, Urakami H (1986) Diffusion of nonelectrolytes through wood saturated with water III. Diffusion rates of polyethylene glycols. Mokuzai Gakkaishi 32(3):147-154

23. Jacobson A (2006) Diffusion of chemicals into green wood. PhD Thesis, Georgia Institute of Technology, Atlanta, USA
24. Tanaka S, Seki M, Miki T, Umemura K, Kanayama K (2017) Solute diffusion into cell walls in solution-impregnated wood under conditioning process III: effect of relative humidity schedule on solute diffusion into shrinking cell walls. J Wood Sci 63:263-270

25. Burr HD, Stamm AJ (1947) Diffusion in wood. J Phys Colloid Chem 51:240-261

26. Bamber RK, Fukazawa F (1985) Sapwood and heartwood: a review. For Abstr 46:567-580

27. Becker G (1976) Treatment of wood by diffusion of salts. Jour Inst Wood Sci 7:30-36

28. Tanaka S, Seki M, Miki T, Shigematsu I, Kanayama K (2015) Solute diffusion into cell walls in solution-impregnated wood under conditioning process I: Effect of relative humidity on solute diffusivity. J Wood Sci 61:543-551

29. Unger A, Schniewind AP, Unger W (2001) Conservation of wood artifacts. Springer, Berlin Heidelb

30. Kaye B (1995) Conservation of waterlogged archaeological wood. Chem Soc Rev 24:35-43

31. Jensen P, Gregory DJ (2006) Selected physical parameters to characterize the state of preservation of waterlogged archaeological wood: A practical guide for their determination. J Archaeol Sci 33:551-559

32. TAPPI (1999) Water solubility of wood and pulp. T207cm-99. TAPPI Press, Atlanta

33. TAPPI (2007) Solvent extractives of wood and pulp. T204C. TAPPI Press, Atlanta

34. TAPPI (1998) Acid-insoluble lignin in wood and pulp. In: T222 om-98. TAPPI Press, Atlanta

35. TAPPI (2011) Holocellulose in wood. T9m-54. TAPPI Press, Atlanta

36. TAPPI (1999) Alpha-, beta- and gamma-cellulose in pulp. T203C. TAPPI Press, Atlanta

37. Dean LR, Jones AM, Jones EBG (1997) Diffusion rates of PEG into wet archaeological oak. In: Proc 6th ICOM Work Gr Wet Org Archaeol Mater Conf, York, pp 435-448

38. Rowell R (1984) The chemistry of solid wood. American Chemical Society, Washington DC

39. Imamura H (1989) Contribution of extractives to wood characteristics. In: Rowe JW (ed) Natural products of woody plants. Springer series in wood science. Springer-Berlin, Heidelberg, pp 843-860

40. Nguyen TD, Nishimura H, Imai T, Watanabe T, Kohdzuma Y, Sugiyama J (2018) Natural durability of the culturally and historically important timber: Erythrophleum fordii wood against white-rot fungi. J Wood Sci 64(3):301-310

41. Young GS, Sims R (1987) Microscopical determination of polyethylene glycol in treated wood-the effect of distribution on dimensional stabilization. In: Proc ICOMC Working Gr Wet Org Archaeol Mater Metals, Freemantle, Australia, pp 109-140

42. Butterfiel BG, Meylan BA (1980) Three-dimensional structure of wood. An ultrastructural approach. Chapman and Hall, London

43. Robertson MB, Packer KJ (1996) Diffusion of $\mathrm{D}_{2} \mathrm{O}$ in archaeological wood measured by ${ }^{1} \mathrm{D}$ NMR profiles. Appl Magn Reson 17:49-64

44. Schweingruber FH (2007) Wood structure and environment. Springer, Berlin 